\title{
Novel distribution records and molecular data for species of Macrogyrodactylus Malmberg, 1957 (Monogenea: Gyrodactyl- idae) from Clarias gariepinus (Burchell) (Siluriformes: Clarii- dae) in southern Africa
}

\author{
Marliese Truter $^{1,2 *(D)}$, Aline A. Acosta ${ }^{1(D)}$, Olaf L. F. Weyl ${ }^{2+}$ and Nico J. Smit $^{(\mathbb{D})}$ \\ ${ }^{1}$ Water Research Group, Unit for Environmental Sciences and Management, North-West University, Potchefstroom, South Africa; \\ ${ }^{2}$ DSI/NRF Research Chair in Inland Fisheries and Freshwater Ecology, South African Institute for Aquatic Biodiversity, Makhanda, \\ South Africa \\ Deceased
}

\begin{abstract}
The viviparous gyrodactylid genus Macrogyrodactylus Malmberg, 1957 is endemic to Africa, composed of nine species from hosts of four freshwater fish families, including catfishes (Siluriformes: Clariidae). Three species, Macrogyrodactylus clarii Gussev, 1961; M. congolensis (Prudhoe, 1957) and M. karibae Douëllou et Chishawa, 1995, are primarily known to parasitise the African sharptooth catfish Clarias gariepinus (Burchell) in various African countries. From November 2017 to September 2019, a total of 184 individuals of $C$. gariepinus were collected from selected localities in southern Africa and their skin, fins and gills were surveyed for monogeneans. Three species of Macrogyrodactylus (M. clarii, M. congolensis and M. karibae) were found parasitising C. gariepinus from five localities in South Africa and Zambia. Overall prevalence was 50\% to 100\% with intensities of up to 109 parasites per host individual. New locality records in southern Africa, morphological observations and additional molecular data on the complete Internal Transcriber Spacer (ITS-1-5.8S-ITS-2) regions of the rDNA gene for the three gyrodactylid species are presented in this study.
\end{abstract}

Keywords: fish parasites, gyrodactylids, endemic species, ITS region, phylogeny

Macrogyrodactylus Malmberg, 1957 (Gyrodactylidae) is one of the six endemic viviparous monogenean genera parasitising African freshwater fishes (Barson et al. 2010, Přikrylová et al. 2017, Řehulková et al. 2018). The genus comprises nine species parasitising hosts from the Anabantidae, Clariidae, Latidae and Polypteridae (Table 1). In addition to the nine species, a study on macrogyrodactylids from Clarias gariepinus (Burchell) in Kenya and Zimbabwe revealed a species possessing morphological features of Macrogyrodactylus clarii Gussev, 1961 and Macrogyrodactylus heterobranchii N'Douba et Lambert, 1999. Molecular characterisation of these specimens suggested a hybrid origin partially corresponding to the ribosomal $18 \mathrm{~S}$, Internal Transcribed Spacer (ITS), and mitochondrial (cox1) gene regions of M. clarii and M. heterobranchii (see Barson et al. 2010).

The majority of the literature on the species of Macrogyrodactylus originate from the Nilo-Sudanian, Abyssian Highlands and Zambezi ichthyofaunal provinces where C. gariepinus is highly valued in aquaculture and as food. Interest on this parasitic group was initially driven by its potential to exponentially increase in infection, first noted on grey bichir, Polypterus senegalus Cuvier, in the Sudan infected with Macrogyrodactylus polypteri Malmberg, 1957, and on C. gariepinus and Heterobranchus longifilis Valenciennes reared in earthen ponds in Nigeria. These infections were characterised by increased mucous secretion, skin damage resulting in the formation of white patches on the skin, increased turbidity of the water, and in some cases death of the host (Amirthalingam 1965, Khalil 1964, 1970, Saoud and Mageed 1969, Obiekezie and Ajah 1994). Later in southern Africa, similar infections on the clariid host $C$. gariepinus were observed in natural conditions and greyish-white patches were noted on the skin of the infected hosts (Khalil and Mashego 1998).

Despite the small number of species in the genus, ample research has been published on the occurrence, morphology and ultrastructure, microhabitat and infection dynamics of some species in natural systems, earthen ponds and in aquaculture conditions (El-Naggar and Serag 1987, Cable et al. 1996, Khalil and Mashego 1998, Arafa 2000, El-Naggar et al. 2001a,b, 2004a, 2019, El-Naggar and Cable 2007, Madanire-Moyo et al. 2010, Arafa et al. 2012, 2013).

Address for correspondence: Marliese Truter, Water Research Group, Unit for Environmental Sciences and Management, North-West University, Private Bag X6001, Potchefstroom, 2520, South Africa. Email: 23378123@student.g.nwu.ac.za 
Table 1. Species of Macrogyrodactylus Malmberg, 1957 from Africa with their host range.

\begin{tabular}{|c|c|c|c|c|}
\hline & Type host & Type locality & Other hosts & Reference \\
\hline Macrogyrodactylus clarii Gussev, 1961 & Clarias sp. & Ghana & \multicolumn{2}{|c|}{$\begin{array}{l}\begin{array}{l}\text { C. anguillaris (Linnaeus) Gussev 1961, Paperna 1969, } \\
\text { C. gariepinus } \\
\text { Shotter 1980, El-Naggar and }\end{array} \\
\text { Serag 1987 }\end{array}$} \\
\hline M. congolensis (Prudhoe, 1957) & \multicolumn{3}{|c|}{$\begin{array}{c}\text { Clarias gariepinus (Burchell) Democratic Republic C. anguillaris } \\
\text { of the Congo }\end{array}$} & $\begin{array}{l}\text { Prudhoe 1957, Thurston } 1970 \text {, } \\
\text { Paperna 1979, Přikrylová and } \\
\text { Gelnar } 2008\end{array}$ \\
\hline $\begin{array}{l}\text { M. heterobranchii N'Douba et Lambert, } \\
1999\end{array}$ & $\begin{array}{l}\text { Heterobranchus longifilis } \\
\text { Valenciennes }\end{array}$ & Senegal & C. anguillaris & $\begin{array}{l}\text { N'Douba and Lambert } 1999 \text {, } \\
\text { Přikrylová and Gelnar } 2008\end{array}$ \\
\hline M. karibae Douëllou et Chishawa, 1995 & C. gariepinus & Zimbabwe & - & $\begin{array}{l}\text { Douëllou and Chishawa 1995, } \\
\text { Khalil and Mashego } 1998\end{array}$ \\
\hline M. polypteri Malmberg, 1957 & Polypterus senegalus Cuvier & Gambia & P. bichir Lacépède & Malmberg 1957 \\
\hline $\begin{array}{l}\text { M. simentiensis Přikrylová et Gelnar, } 2008 \\
\text { Species inquirenda }\end{array}$ & P. senegalus & Senegal & - & Přikrylová and Gelnar 2008 \\
\hline M. anabantii Paperna, 1973 & \multicolumn{2}{|c|}{ Ctenopoma muriei Boulenger Uganda } & - & Paperna 1973 \\
\hline M. ctenopomii Paperna, 1973 & C. muriei (Boulenger) & Uganda & - & Paperna 1973 \\
\hline M. latesi Paperna, 1969 & Lates niloticus (Linnaeus) & Ghana & - & Paperna 1969 \\
\hline
\end{tabular}

Table 2. Localities, number $(\mathrm{N})$ of host individuals screened, host status and whether infected with Macrogyrodactylus spp. or not of 184 Clarias gariepinus (Burchell) collected from November 2017 to September 2019 in southern Africa.

\begin{tabular}{|c|c|c|c|c|c|}
\hline Locality & Province & Host introduction status & Coordinates & $\mathrm{N}$ & $\begin{array}{l}\text { Infected by one or more } \\
\text { Macrogyrodactylus spp. }\end{array}$ \\
\hline \multicolumn{6}{|l|}{ South Africa } \\
\hline Riviersonderend River & Western Cape & Translocated & $34.0998 \mathrm{~S}, 19.6656 \mathrm{E}$ & 15 & No \\
\hline Great Fish River & Eastern Cape & Translocated & $33.1543 \mathrm{~S}, 26.8320 \mathrm{E}$ & 11 & No \\
\hline Gariep Dam (Orange River) & Free State & Native & $30.5682 \mathrm{~S}, 25.5647 \mathrm{E}$ & 15 & No \\
\hline Riet River & Free State & Native & $29.5700 \mathrm{~S}, 25.3042 \mathrm{E}$ & 12 & No \\
\hline Sand River & Free State & Native & $28.3232 \mathrm{~S}, 27.3597 \mathrm{E}$ & 15 & No \\
\hline Vaal River & North West & Native & $26.8665 \mathrm{~S}, 27.2944 \mathrm{E}$ & 18 & Yes \\
\hline Boskop Dam (Mooi River) & North West & Native & $26.5621 \mathrm{~S}, 27.1181 \mathrm{E}$ & 15 & Yes \\
\hline Ndumo Game Reserve & KwaZulu-Natal & & & & \\
\hline KuShokwe Pan & & Native & $26.8717 \mathrm{~S}, 32.2141 \mathrm{E}$ & 15 & Yes \\
\hline Nyamithi Pan & & Native & $26.8829 \mathrm{~S}, 32.3113 \mathrm{E}$ & 15 & Yes \\
\hline Phongolo River & & Native & $26.9297 \mathrm{~S}, 32.3238 \mathrm{E}$ & 4 & No \\
\hline Usuthu River & & Native & $26.8824 \mathrm{~S}, 32.3116 \mathrm{E}$ & 3 & Yes \\
\hline \multicolumn{6}{|l|}{ Zambia } \\
\hline Kabompo River & Northern & Native & $13.1025 \mathrm{~S}, 24.6920 \mathrm{E}$ & 2 & Yes \\
\hline Barotse floodplain & Northwestern & Native & $15.1960 \mathrm{~S}, 22.9647 \mathrm{E}$ & 17 & Yes \\
\hline
\end{tabular}

Increasing interest in the endemic species of gyrodactylids is the outcome of potential undiscovered high diversity, including morphological and molecular features that are suitable for advanced phylogenetic, evolutionary and parasite-host relationship studies (Bakke et al. 2002, Cribb et al. 2002, Poulin 2002, Boeger et al. 2003, Barson et al. 2010, Přikrylová et al. 2013). Although host specificity for all known species of Macrogyrodactylus has not been determined, specificity of $M$. polypteri towards bichirs has been confirmed, as only Polypterus bichir Lacépède and P. senegalus have been reported as hosts (Khalil 1964), and an affinity towards clariid hosts seems evident for three species of Macrogyrodactylus. Additionally, Barson et al. (2008) noted that M. clarii, Macrogyrodactylus congolensis (Prudhoe, 1957) and Macrogyrodactylus karibae Douëllou et Chishawa, 1995 exhibit a certain degree of specificity towards $C$. gariepinus.

In southern Africa, studies on macrogyrodactylids were initiated during the 1990's. Khalil and Mashego (1998) documented taxonomically significant features for the genus and provided a measurement scheme highlighting the sclerotised haptoral structures and cirrus spines. It is only in the last two decades that studies on the systematics of Macrogyrodactylus and other genera of endemic gyrodac- tylid species in Africa emerged (Matějusová et al. 2003, Barson et al. 2008, 2010, Přikrylová and Gelnar 2008, Vanhove et al. 2011, 2018, Přikrylová et al. 2013). The aforementioned authors emphasise the importance of studies of the morphological characters, distribution and genetics of these parasites.

This study presents novel distribution records for M. clarii, M. congolensis and M. karibae from C. gariepinus in southern Africa, as well as additional morphological observations and molecular data (ITS-1-5.8S-ITS-2 regions of the rDNA gene).

\section{MATERIAL AND METHODS}

\section{Collection of hosts and parasites}

A total of 184 individuals of Clarias gariepinus were collected from November 2017 to September 2019 at various localities in southern Africa (see Table 2 and Fig. 1A,B). Individual hosts were euthanised by percussive stunning and severance of the spinal cord (ethics Nos. NWU-00156-18-A5, NWU-00264-15-A5) and subjected to a full parasitological screening for metazoan parasites (see detailed procedures in Řehulková 2018). Herein, we report only on the infection with species of Macrogyrodactylus found on the skin and gills of the host. Whole specimens of 


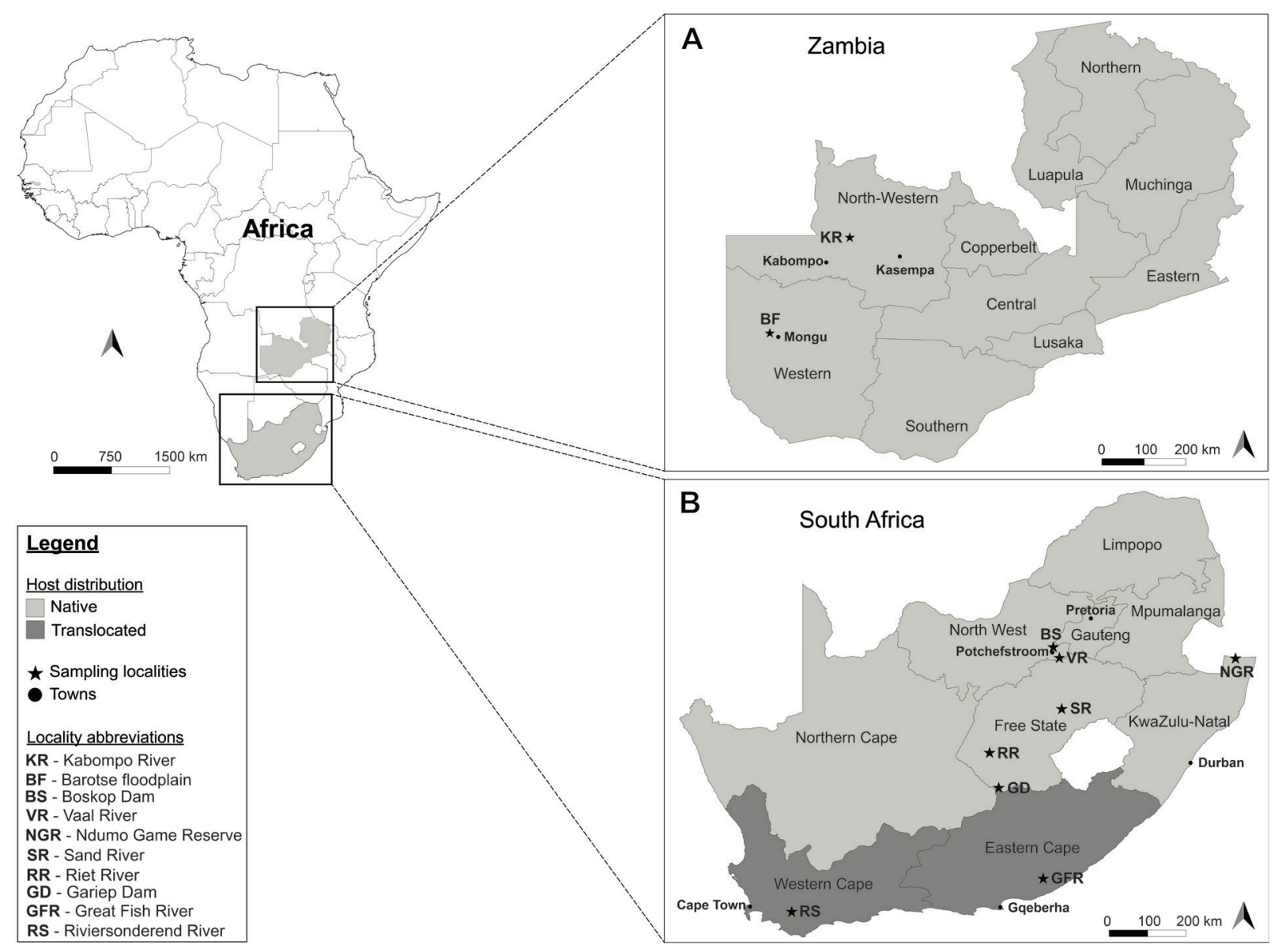

Fig. 1. Map illustrating the sampling localities of Clarias gariepinus (Burchell) during the present study. A-Zambia; B - South Africa.

Table 3. Information on the sequences of Macrogyrodactylus spp. (Monogenea: Gyrodactylidae) used in the phylogenetic analyses of the ITS1-5.8S-ITS2 region of the rRNA gene. Laminiscus gussevi (Bychowsky et Polyansky, 1953) was used as outgroup. Species sequenced in this study are in bold.

\begin{tabular}{|c|c|c|c|c|}
\hline Species & Host & Locality & GenBank ID & Reference \\
\hline$\overline{\text { Macrogyrodactylus clarii (Isolate 1) }}$ & Clarias gariepinus & Barotse floodplain, Zambia & MZ869846 & Present study \\
\hline M. clarii (Isolate 2) & Clarias gariepinus & Barotse floodplain, Zambia & MZ869850 & Present study \\
\hline M. clarii (Isolate 3) & Clarias gariepinus & Barotse floodplain, Zambia & MZ869847 & Present study \\
\hline M. clarii (Isolate 1) & Clarias gariepinus & Phongolo River floodplain, SA & MZ869849 & Present study \\
\hline M. clarii & Clarias gariepinus & Save River, Zimbabwe & GU252711 & Barson et al. 2010 \\
\hline M. clarii $\times$ heterobranchii & Clarias gariepinus & Save River, Zimbabwe & GU252712 & Barson et al. 2010 \\
\hline M. clarii $\times$ heterobranchii & Clarias gariepinus & Lake Turkana, Kenya & GU252713 & Barson et al. 2010 \\
\hline M. clarii $\times$ heterobranchii & Heterobranchus bidorsalis & Lake Turkana, Kenya & HF548683 & Přikrylová et al. 2013 \\
\hline Macrogyrodactylus heterobranchii & Clarias anguillaris & Gambia River, Senegal & GU252714 & Barson et al. 2010 \\
\hline Macrogyrodactylus congolensis & Clarias anguillaris & Lake Turkana, Kenya & GU252716 & Barson et al. 2010 \\
\hline M. congolensis & Clarias anguillaris & Mare Simenti, Senegal & GU252717 & Barson et al. 2010 \\
\hline M. congolensis & Clarias gariepinus & Vaal River, SA & MZ869848 & Present study \\
\hline Macrogyrodactylus karibae & Clarias gariepinus & Save River, Zimbabwe & GU252715 & Barson et al. 2010 \\
\hline M. karibae & Clarias gariepinus & Barotse floodplain, Zambia & MZ869845 & Present study \\
\hline M. karibae & Clarias gariepinus & Phongolo River floodplain, SA & MZ869851 & Present study \\
\hline Macrogyrodactylus polypteri & Polypterus senegalus & - & AJ567672 & Matějusová et al. 2003 \\
\hline Macrogyrodactylus simentiensis & Polypterus senegalus & Mare Simenti, Senegal & HF548681 & Přikrylová et al. 2013 \\
\hline Laminiscus gussevi & Mallotus villosus & Iceland & HF548678 & Přikrylová et al. 2013 \\
\hline
\end{tabular}

Abbreviations: SA - South Africa.

Macrogyrodactylus spp. from parasitised fish were removed from the skin or gills using fine dissecting needles and cleared on a microscope slide in glycerine-ammonium picrate (GAP - Malmberg 1970) for later morphological identification, which were subsequently remounted in Canada Balsam, following the procedure described in Ergens (1969).
For molecular characterisation, specimens were fixed in $96 \%$ molecular-grade ethanol and processed as described below. The taxonomical relevant sclerites of individuals were measured using a Nikon Eclipse $\mathrm{N} i$ compound microscope (Nikon Instruments, Tokyo, Japan) with DIC optics. Measurements were taken using NIS-Elements BR $4.60^{\circ}$ software and line drawings of 

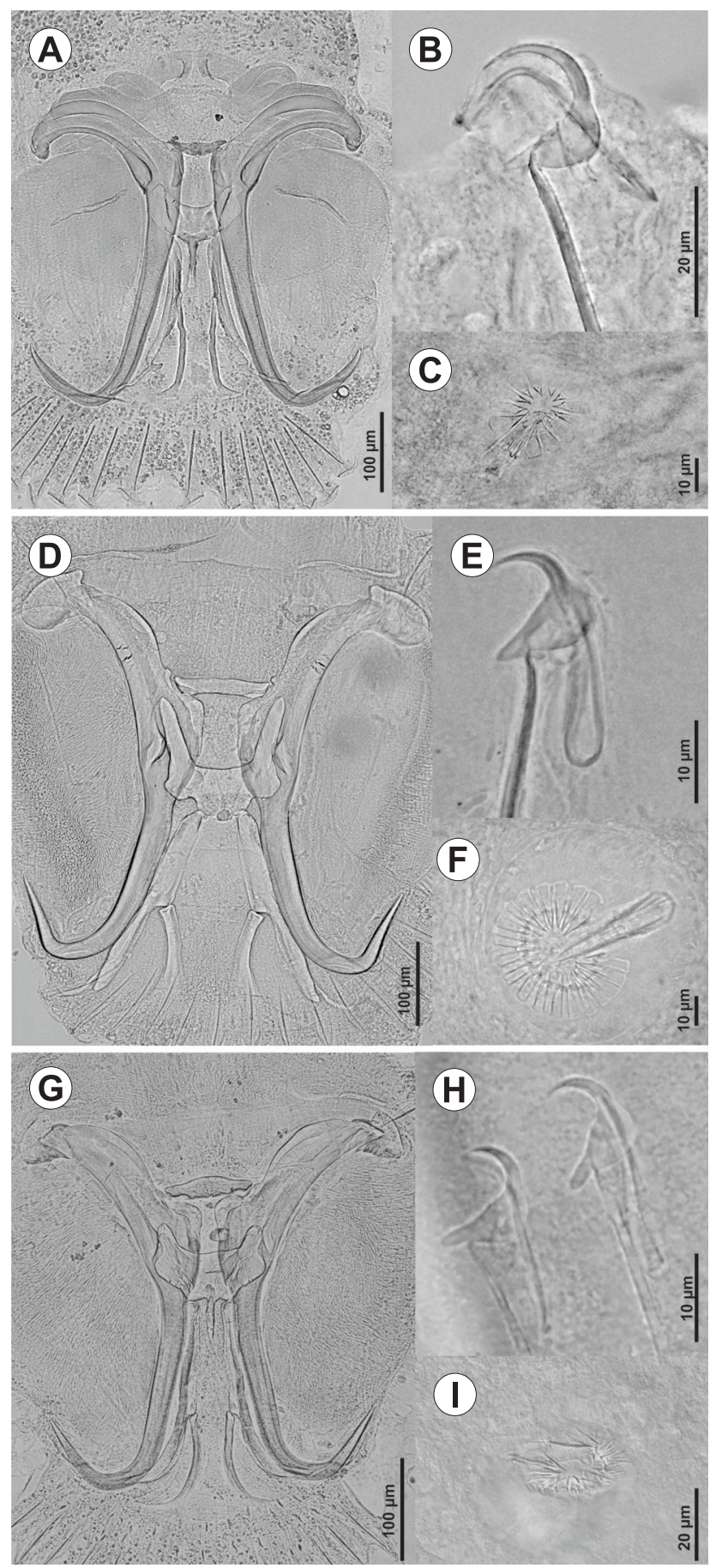

Fig. 2. Micrographs showing the morphological features of Macrogyrodactylus clarii Gussev, 1961 (A-C), M. congolensis (Prudhoe, 1957) (D-F), and M. karibae Douëllou et Chishawa, 1995 $(\mathrm{G}, \mathrm{H}) . \mathbf{A}, \mathbf{D}, \mathbf{G}-$ hamuli complex; $\mathbf{B}, \mathbf{E}, \mathbf{H}$ - sickle of marginal hook; $\mathbf{C}, \mathbf{F}, \mathbf{I}-$ cirrus with spines.

sclerotised structures were made with the aid of a camera lucida attached to the microscope and digitalised using a Wacom Intuos ${ }^{\mathbb{R}}$ Pro drawing tablet (Wacom, Saitana, Japan) and Adobe Illustrator ${ }^{\mathrm{TM}}$ software package.

Measurements of sclerotised structures were performed according to Khalil and Mashego (1998), N'Douba and Lambert (1999), and Přikrylová and Gelnar (2008). Morphometric data are presented as mean followed by range in parentheses. All measurements are in micrometres unless otherwise indicated.
Whole-mounted voucher specimens were deposited in the parasite collection of the National Museum, Bloemfontein (NMB), South Africa. Ecological descriptors for the monogenean parasites (prevalence and mean intensity) followed Bush et al. (1997).

\section{DNA extraction, PCR amplification and sequence analyses}

The specimens used for molecular analyses had the haptor mounted on slides with GAP to confirm morphological identity (see Řehulková 2018) and deposited as e-vouchers and molecular vouchers (hologenophore, see Pleijel et al. 2008 for terminology). Thereafter, the anterior section of the parasite was used for DNA extraction using PCRBIO Rapid Extraction $($ ) (ThermoFischer Scientific, Waltham, Massachusetts, USA) kit following the manufacturer's protocol. DNA amplifications were performed on the Internal Transcriber Spacer ITS1-5.8S-ITS2 regions of the rRNA gene using the primers ITS1A (5'-GTAACAAGGTTTCCGTAGGTG-3') and ITS2 (5'-TCCTCCGCTTAGTGATA-3') (Matějusová et al. 2001). Each amplification reaction was performed with a total volume of $25 \mu \mathrm{l}: 12.5 \mu \mathrm{l}$ of DreamTaq PCR Master Mix (2X) (ThermoFischer Scientific, Waltham, Massachusetts, USA), $1 \mu 1$ of $10 \mu \mathrm{M}$ of each primer, $1 \mu$ l of DNA product and 9.5 $\mu \mathrm{l}$ of double distilled water. Thermocycling conditions followed Barson et al. (2010). PCR products were visually inspected on a 1\% agarose gel electrophoresis and sent to Inqaba Biotechnical Industries (Pty) Ltd. (Pretoria, South Africa) for purification and sequencing. Basic Local Alignment Search Tool (BLAST) (https://blast.ncbi.nlm.nih.govhttps://blast.ncbi.nlm.nih.gov) was used to compare and identify species closely related to the new sequences.

Seven newly generated sequences of Macrogyrodactylus spp. were aligned with those of ten other congeneric species available in GenBank, and one sequence of Laminiscus gussevi (Bychowsky et Polyansky, 1953) used as outgroup (see Table 3 for detailed information on the sequences). The alignment was generated in Geneious v. 7.1.3 using implemented default parameters of MUSCLE (Kearse et al. 2012). The alignment was trimmed, resulting in the lenght of $810 \mathrm{bp}$. Evolutionary model selection was performed in MEGA 7 (Kumar et al. 2016). Phylogenetic analyses were run under Maximum Likelihood (ML) and Bayesian Inference (BI) criteria, applying the model of nucleotide evolution GTR + G. ML trees were generated in RAxML (Guindon and Gascuel 2003). The model parameters and bootstrap support values (1,000 repetitions) were estimated using RAxML. BI trees were generated in MrBayes (Ronquist et al. 2012), running two independent MCMC runs of four chains for 10 million generations and sampling tree topologies every 1,000 generations. Burnin periods were set to the first 25,000 generations. ML and BI analyses were performed on the computational resource CIPRES (Miller et al. 2010). Genetic divergences were calculated using uncorrected p-distances model in MEGA 7 and are expressed as percentage (p-distances) and differences in number of nucleotides. Trees were visualised in FigTree v1.4.4 (Rambaut 2009).

\section{RESULTS}

In the present study, Macrogyrodactylus clarii, M. congolensis and M. karibae were found on the skin and gills of Clarias gariepinus from five localities in southern Africa (Table 2). Infection of C. gariepinus with species of Macrogyrodactylus are recorded for the first time from the Vaal 
A

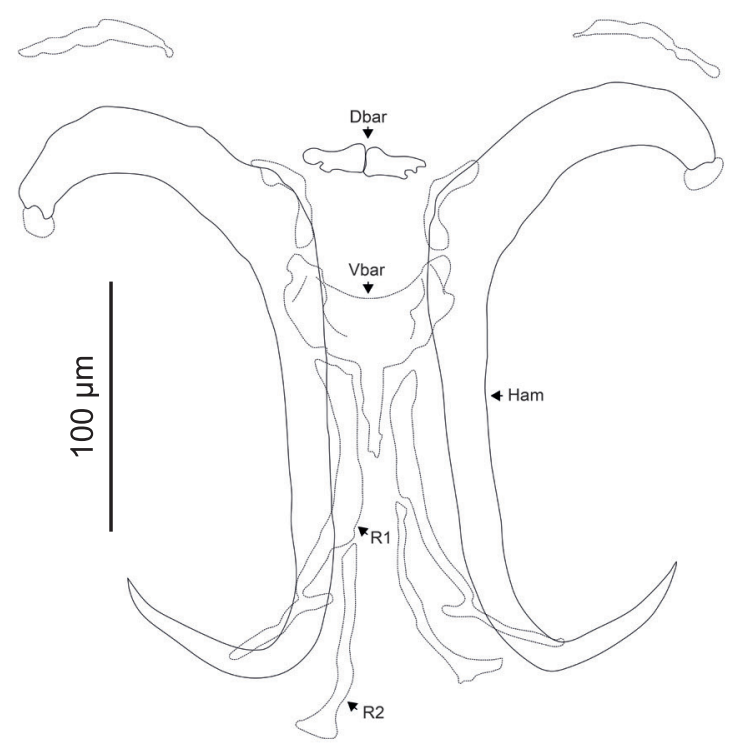

C

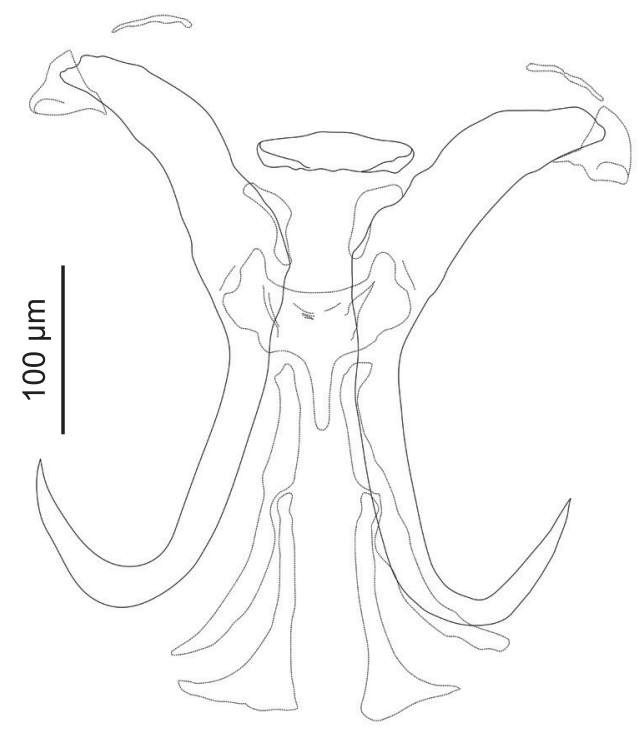

B

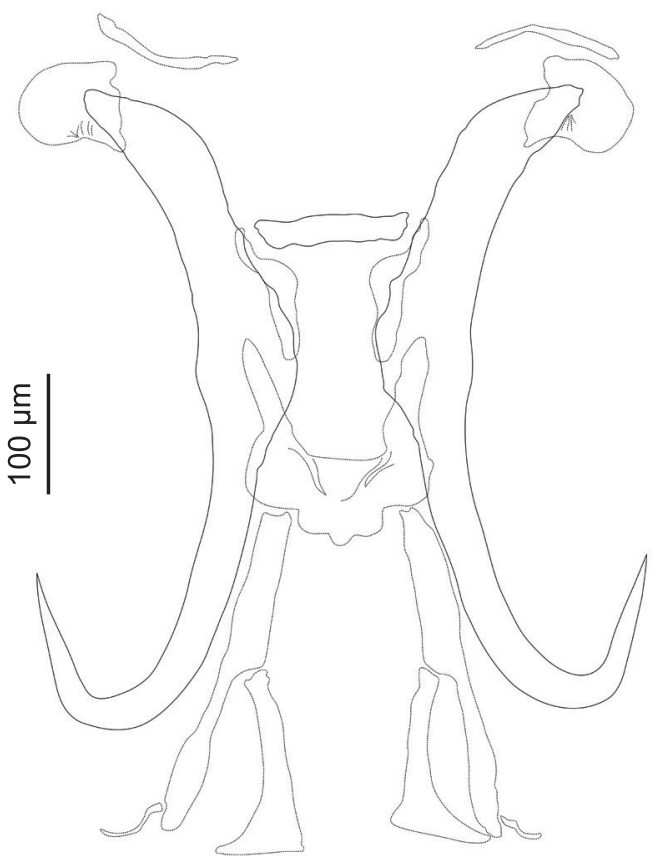

D
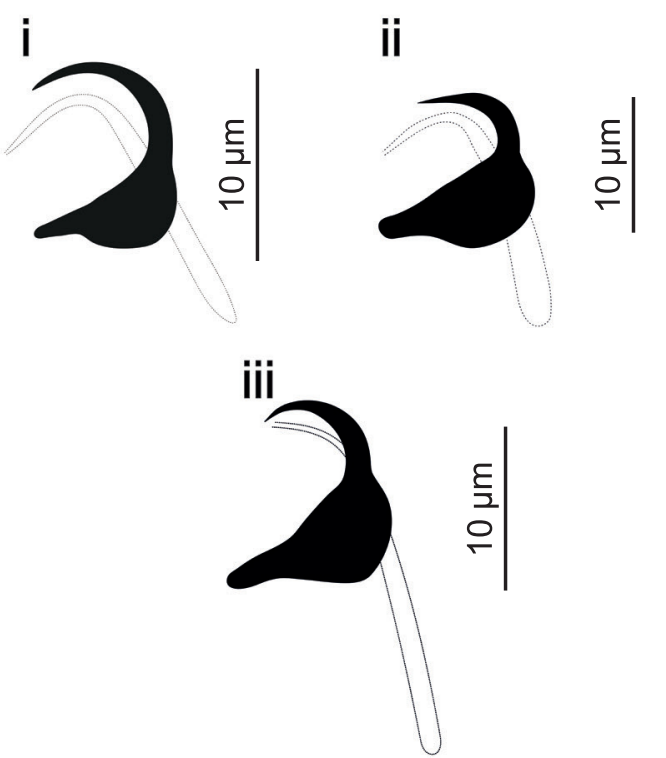

Fig. 3. Illustrations of the hamuli of Macrogyrodactylus clarii Gussev, 1961 (A); M. congolensis (Prudhoe, 1957) (B); M. karibae Douëllou et Chishawa, 1995 (C). D - sickle of marginal hooks of M. clarii (i), M. congolensis (ii), and M. karibae (iii). Abbreviations: Ham - hamuli, Vbar - ventral bar, Dbar - dorsal bar, R1 and R2 - ventral bar rod-like sclerites.

River (North West Province) and Ndumo Game Reserve (NGR) (KwaZulu-Natal Province), in South Africa (SA), and the Kabompo and Zambezi (Barotse floodplain) rivers in Zambia (ZM). The southernmost distribution records for M. clarii and M. karibae are recorded from NGR and for M. congolensis from the Vaal River (SA). All three species were present from sites within the NGR and Barotse floodplain, whereas no other species co-occurred with M. congolensis in the Vaal and Kabompo rivers.

Macrogyrodactylus congolensis was the most widely distributed species occurring at four of the five localities, followed by $M$. karibae (three localities), and M. clarii (two localities). The least prevalent and abundant species was
M. karibae, except in NGR where it was found to co-occur with M. congolensis. Macrogyrodactylus clarii was the most prevalent and abundant species even when in co-occurrence with the other two species found during this study in NGR and the Barotse floodplain. The highest intensity of infection was recorded from the Vaal River, with 109 individuals of $M$. congolensis found on a single host, and the same intensity of infection for an individual host was noted from the Barotse floodplain. However, no greyish-white mucous covering of the skin was observed. In the present study, the general morphology and morphometrics for M. clarii, M. congolensis and $M$. karibae corresponded with those from original descriptions and redescriptions for each species. 
Table 4. Morphometric comparison of Macrogyrodactylus clarii Gussev, 1961 parasitising Clarias gariepinus (Burchell) in Africa. Measurements are presented in micrometres (except body lenght) as mean followed by range in parentheses.

\begin{tabular}{|c|c|c|c|c|c|}
\hline & $\begin{array}{l}\text { KuShokwe Pan } \\
\text { SA } \\
\mathrm{n}=48 \\
\text { Present study }\end{array}$ & $\begin{array}{c}\text { Barotse floodplain } \\
\qquad \begin{array}{c}\text { ZM } \\
n=25 \\
\text { Present study }\end{array}\end{array}$ & $\begin{array}{l}\text { Lake Turkana \& } \\
\text { Lake Chivero } \\
\text { KY / ZI } \\
n=10 \\
\text { Barson et al. } 2010\end{array}$ & $\begin{array}{c}\text { Nile Delta } \\
\text { EG } \\
n=10 \\
\text { El-Naggar and Serag } 1987\end{array}$ & $\begin{array}{c}\text { Middle Letaba Dam } \\
\text { SA } \\
- \\
\text { Khalil and Mashego } 1998\end{array}$ \\
\hline \multicolumn{6}{|l|}{ Body } \\
\hline length (mm) & $3.39(2.19-5.01)$ & $3.17(2.24-4.35)$ & - & $2.33(2.00-2.58)$ & $1.80-2.60$ \\
\hline Width & $518(221-788)$ & $382(278-584)$ & - & $400(360-440)$ & $320-440$ \\
\hline \multicolumn{6}{|l|}{ Haptor } \\
\hline length & 839 (544-1377) & $680(465-846)$ & - & $460(400-500)$ & - \\
\hline width & $600(420-1053)$ & $352(306-583)$ & - & $440(400-480)$ & - \\
\hline \multicolumn{6}{|l|}{ Hamuli } \\
\hline total length & $370(193-465)$ & $426(378-497)$ & $436(374-475)$ & $385(376-392)$ & $437-453$ \\
\hline point length & $113(98-134)$ & $153(110-143)$ & $120(108-136)$ & $120(112-128)$ & $131-140$ \\
\hline shaft length & $334(281-411)$ & $376(340-440)$ & $380(350-457)$ & - & $381-406$ \\
\hline root length & $171(139-218)$ & $197(156-222)$ & $191(135-238)$ & $171(176-184)$ & 193-203 \\
\hline \multicolumn{6}{|l|}{ Ventral bar } \\
\hline anterior lateral arm & $28(17-38)$ & $33(23-43)$ & $29(17-38)$ & - & $21-31$ \\
\hline posterior central arm & $63(44-80)$ & $74(59-90)$ & $69(61-85)$ & - & $46-55$ \\
\hline total length & $135(110-166)$ & $152(122-175)$ & $148(137-172)$ & $110(104-116)$ & - \\
\hline total width & $111(89-135)$ & $112(106-133)$ & $138(122-157)$ & $106(96-112)$ & - \\
\hline ventral bar R1 & $250(192-301)$ & $272(232-304)$ & $191(177-207)$ & - & - \\
\hline ventral bar R2 & $137(111-185)$ & $152(129-170)$ & $147(141-157)$ & - & - \\
\hline Dorsal bar & divided & divided & divided & divided & divided \\
\hline total length & $18(12-23)$ & $18(14-22)$ & $16.5(13.5-20)$ & - & $15-18$ \\
\hline total width & 77 (61-93) & $78(68-92)$ & $82.3(72.5-92)$ & - & $68-75$ \\
\hline \multicolumn{6}{|l|}{ Marginal hooks } \\
\hline handle length & $92(72-108)$ & $100(84-112)$ & $96(87.5-112)$ & 82 & - \\
\hline sickle length & $17(13-21)$ & $18(15-20)$ & $18.5(17-21)$ & 14 & - \\
\hline sickle proximal width & $12(8-14)$ & $13(9-16)$ & $13.8(13-17)$ & - & - \\
\hline Cirrus spines & $13-15$ & $13-15$ & - & 12 & $12-13$ \\
\hline
\end{tabular}

Abbreviations: EG - Egypt; KY - Kenya; SA - South Africa; ZI - Zimbabwe; ZM - Zambia; n - number of specimens studied.

\section{Gyrodactylidae Cobbold, 1864}

\section{Macrogyrodactylus Malmberg, 1957}

\section{Macrogyrodactylus clarii Gussev, 1961}

Figs. 2A-C, 3A,D(i); Table 4

Type host: Clarias sp. (Siluriformes: Clariidae).

Type locality: Lake Awasa, Ethiopia.

Other records: Clarias gariepinus: Egypt - El-Naggar and Serag (1987), El-Naggar (1993), Hagras et al. (1995, 1999), El-Naggar et al. (1997, 2001a,b, 2004a,b, 2016, 2017, 2019, 2020), El-Naggar and Cable (2007), Arafa et al. (2009, 2012), Radwan et al. (2009), El-Seify et al. (2011), Mashalay et al. (2019); Ethiopia - Gussev (1961), Beletew et al. (2016); Ghana - Paperna (1969, 1979); Kenya - Barson et al. (2010); Nigeria - Obiekezie and Ajah (1994), Eyo et al. (2015); South Africa - Khalil and Mashego (1998), Olivier et al. (2009), Madanire-Moyo et al. (2010, 2012), Matla (2012), Mahlatji (2014); Uganda - Paperna (1979); Zimbabwe - Barson et al. (2008, 2010), Madanire-Moyo and Barson (2010). Clarias anguillaris (Linnaeus); Nigeria - Shotter (1980).

Localities (present study): South Africa: KuShokwe Pan, Ndumo Game Reserve, KwaZulu-Natal Province; Zambia: Barotse floodplain, Zambezi River, Northwestern Province.

Site of infection: Skin and gills.

Voucher material: Twenty-three voucher specimens deposited in NMB (Coll. Nos. P 800-809, 820-822).

Representative DNA sequences: $710-753$ bp long sequences of the ITS1-5.8S-ITS2 region of the rRNA gene of four isolates (GenBank accession numbers: MZ869846, MZ869850, MZ869847, MZ869849). Hologenophores: NMB (P 824-827).

Specimens studied: $n=48$ (KuShokwe Pan, South Africa - SA); $\mathrm{n}=25$ (Barotse floodplain, Zambia - ZM).

Infection rate: KuShokwe Pan (SA): Prevalence (P) of $80 \%$ and intensity of infection (IF) 1-12; Barotse floodplain (ZM) $\mathrm{P}=64 \%$, IF $=1-4$.

Morphological observations (measurements provided in Table 4): Morphology of haptoral sclerites conform to description of Gussev (1961) and redescription of El-Naggar and Serag (1987). Individuals armed with 16 marginal hooks, two positioned in anterolateral lobes, 14 in posterior edge of haptor. Basal part of sickle has small indentation near anterior end of base, anterior end of sickle base thin, sharply rounded. Base of sickle rounded with slight curvature on distal side into slender sickle blade curving inward and tapering into a fine, sharp point that stops in line with anterior end of sickle base (see Figs. 2B, 3D(i)). Hamulus complex consisting of a pair of robust hamuli with curvature into point, sharp inward curved root, small dorsal bar consisting of two articulating sclerites, Y-shaped ventral bar with short anterolateral processes and long posterior central arm. Two narrow rod-like sclerites (R1 and R2) accompany ventral bar (Figs. 2A-C, 3A). Cirrus observed in 24 (SA) and 11 (ZM) specimens studied, each armed with 13-15 small spines and one large spine (Fig. 2C). 
Table 5. Morphometric comparison of Macrogyrodactylus congolensis (Prudhoe, 1957) parasitising Clarias gariepinus (Burchell) in Africa. Measurements are presented in micrometres (except body lenght) as mean followed by range in parentheses.

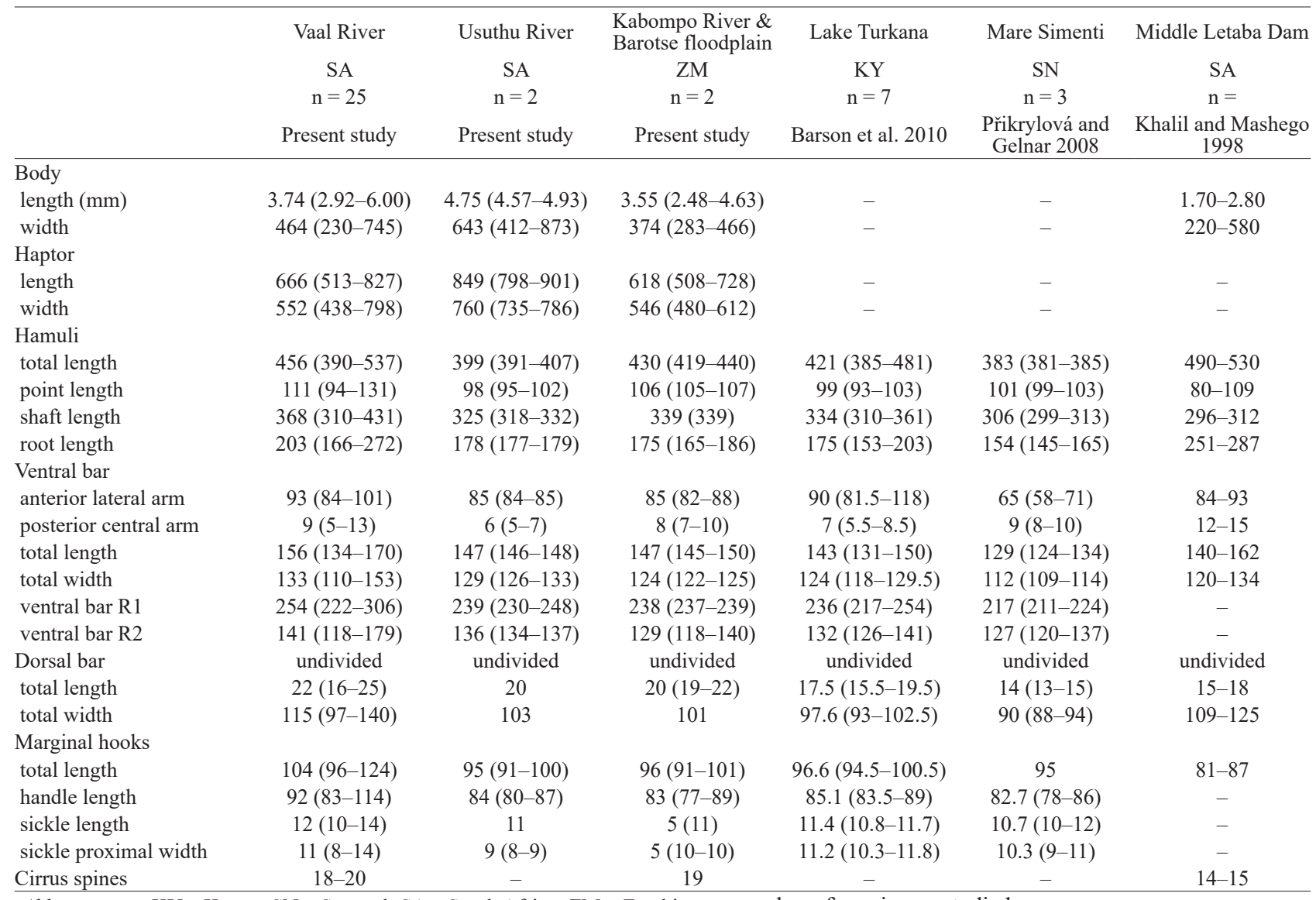

Abbreviations: KY - Kenya; SN - Senegal; SA - South Africa; ZM - Zambia; $\mathrm{n}$ - number of specimens studied.

Remarks. The dimensions of the hamulus (total length and length of the shaft, root and point) from specimens studied from NGR (SA) and Barotse floodplain (ZM) (Table 4) are similar to those of specimens from the Middle Letaba Dam (SA) and localities in Kenya and Egypt (El-Naggar and Serag 1987, Khalil and Mashego 1998, Barson et al. 2010). Dimensions obtained for the dorsal bar in the present study do not deviate from the ranges found in other studies. Marginal hook size also conforms to previously recorded measurements. The marginal hook sickle morphology is identical to that illustrated for $M$. clarii specimens collected from Zimbabwe and M. clarii $\times$ Macrogyrodactylus heterobranchii from Kenya (see Barson et al. 2010). Gussev (1961) and El-Naggar and Serag (1987) reported 16 and 12 cirrus spines, with one large spine in their descriptions, respectively. Additionally, this study provides details on the morphology of the sickle, which was not described by Gussev (1961) and El-Naggar and Serag (1987). Comparative measurements are presented in Table 4.

\section{Macrogyrodactylus congolensis (Prudhoe, 1957) Yama- guti, 1963 Figs. 2D-F, 3B,D(ii); Table 5}

S y n o n y m: Neogyrodactylus congolensis Prudhoe, 1957

Type host: Clarias gariepinus (Burchell) (Siluriformes: Clariidae).

Type locality: Lake Upemba (Lualaba River), Democratic Republic of the Congo.
Other records: Clarias gariepinus: Egypt - El-Naggar et al. (1999, 2001a,b, 2004b, 2007, 2017, 2019), Hagras et al. (1999), Arafa (2000, 2011), Arafa et al. (2003, 2013, 2014), Mashalay et al. (2019); Democratic Republic of the Congo Prudhoe (1957), Vanhove et al. (2018); Kenya - Barson et al. (2010); South Africa - Khalil and Mashego (1998), Madanire-Moyo et al. (2010, 2012); Uganda - Thurston (1970), Akoll et al. (2012). Clarias anguillaris: Senegal - Přikrylová and Gelnar (2008), Barson et al. (2010).

Localities (present study): South Africa: Vaal River, North West Province and Usuthu River, Ndumo Game Reserve (NGR), KwaZulu-Natal Province; Zambia: Barotse floodplain, Zambezi River, Northwestern Province, Kabompo River, Northern Province.

Site of infestation: Skin and gills.

Voucher material: Nineteen voucher specimens deposited in, NMB P 812-817, 823.

Representative DNA sequence: 696 bp long sequence of the ITS1-5.8S-ITS2 region of the rRNA gene of one isolate. GenBank accession number: MZ869848. Hologenophore, NMB P 828.

Specimens studied: $\mathrm{n}=25$ (Vaal River, SA), $\mathrm{n}=2$ (Usuthu River, SA), $\mathrm{n}=1$ (Barotse floodplain, ZM), $\mathrm{n}=1$ (Kabompo River, ZM).

Infection rate: Usuthu River (SA): $\mathrm{P}=3 \%, \mathrm{IF}=1$; Vaal River (SA): $\mathrm{P}=33 \%$, IF $=1-109$; Barotse floodplain (ZM): $\mathrm{P}=$ $6 \%, \mathrm{IF}=1 ;$ Kabompo River $(\mathrm{ZM}): \mathrm{P}=50 \%, \mathrm{IF}=1$. 
Table 6. Morphometric comparison of Macrogyrodactylus karibae Douëllou et Chishawa, 1995 parasitising Clarias gariepinus (Burchell) in Africa. Measurements are presented in micrometres (except body lenght) as mean followed by range in parentheses.

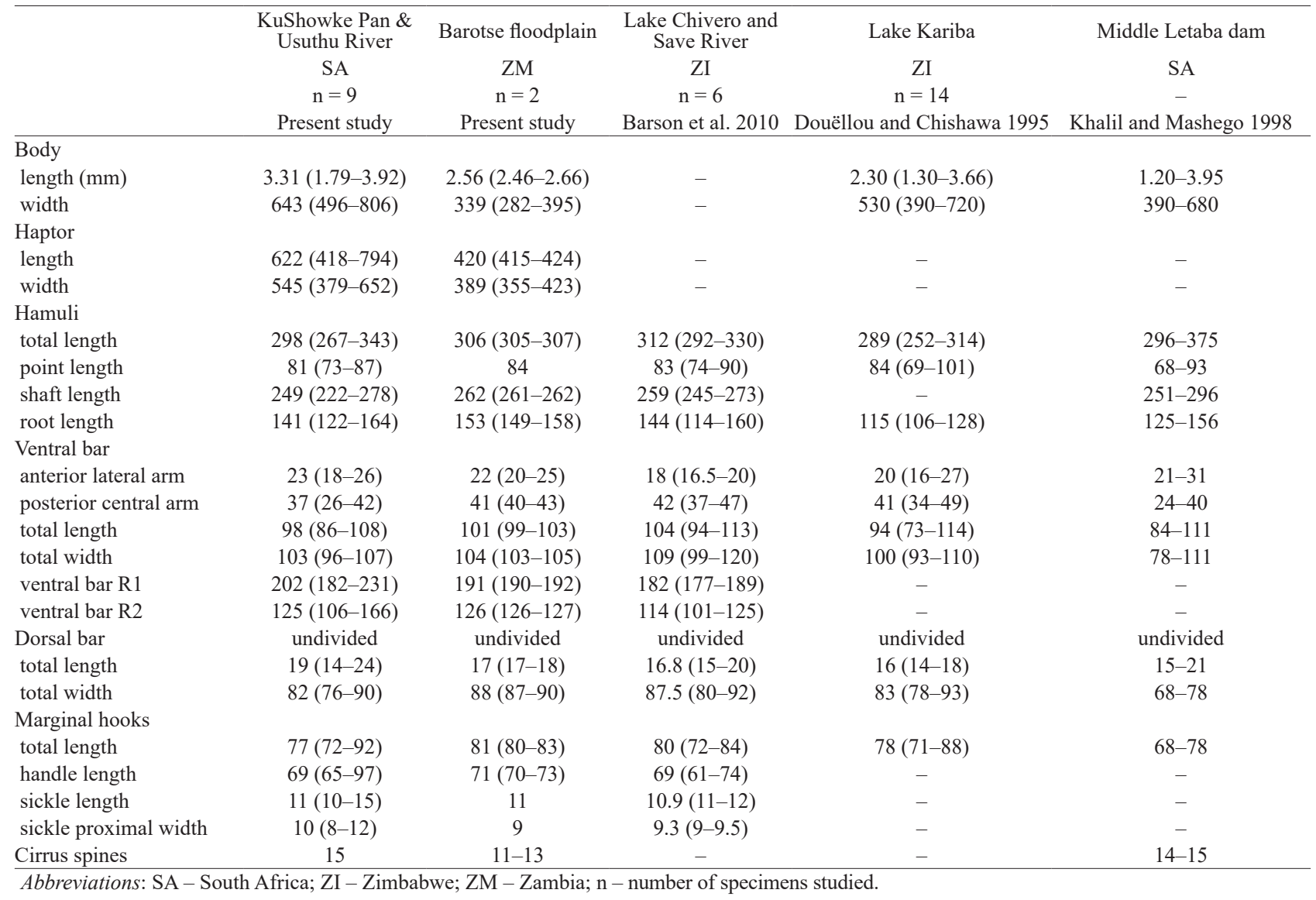

Morphological observations (measurements provided in Table 5): Morphology of haptoral sclerites similar to illustrations provided in description of Prudhoe (1957). Hamulus complex of $M$. congolensis large in size, has slender hamuli less sharply curved into point and root, armed with 16 marginal hooks. Marginal hook sickle robust, with noticeable curvature in base near anterior end of sickle. Anterior end of sickle base rounded and convex, with indentation on distal side as it joins sickle blade that is short, curved inward tapering into a fine point and stops before the proximal end of sickle base (Figs. 2E, 3D(ii)). Hamuli complex has small uniform dorsal bar, wider than long, Y-shaped ventral bar with long anterolateral processes, and short posterior central arm. Two narrow rod-like sclerites accompany ventral bar (Figs. 2D-F, 3B). Cirrus observed in one specimen from the Usuthu River (SA) and Barotse floodplain (ZM), respectively, and 17 individuals from the Vaal River (SA), each armed with 18-20 small spines and one large spine (Fig. 2F).

Remarks. The dimensions of the hamulus (total length and the length of the shaft, root and point) from specimens studied from the Vaal and Usuthu rivers (SA) and the Kabompo River and Barotse floodplain (ZM) are similar in size to specimens from the Middle Letaba Dam and Lake Turkana in Kenya (Khalil and Mashego 1998, Barson et al. 2010). Macrogyrodactylus congolensis specimens from Senegal seems to have smaller hamuli compared to the present and other studies (see Přikrylová and Gelnar 2008). Dimensions obtained for the undivided dorsal bar in the present study do not deviate from the ranges found in other studies. Marginal hook measurements are also in accordance with previously recorded measurements (see Table 5). The morphology of the marginal hook sickle conforms to those illustrated for $M$. congolensis from Kenya (see Barson et al. 2010). Prudhoe (1957) reported fewer cirrus spines (15), with one large spine in his description of $M$. congolensis. Details on the morphology of the marginal hooks were not provided in the description of Prudhoe (1957), which are added in the present study. Comparative measurements are presented in Table 5.

\section{Macrogyrodactylus karibae Douëllou et Chishawa, 1995}

Figs. 2G-I, 3C,D(iii); Table 6

Type host: Clarias gariepinus (Burchell) (Siluriformes: Clariidae).

Type locality: Lake Kariba, Zimbabwe.

O th e r r e c ord s: Clarias gariepinus. South Africa-Khalil and Mashego (1998), Olivier et al. (2009), Matla (2012); Zimbabwe - Douëllou and Chishawa (1995), Barson et al. (2008, 2010).

Localities (present study): South Africa: KuShokwe Pan and Usuthu River, Ndumo Game Reserve, KwaZulu-Natal Province; Zambia: Barotse floodplain, Zambezi River, Northwestern Province.

Site of infection: Skin and gills. 
Table 7. Nucleotide genetic divergence values among sequences of the ITS1-5.8S-ITS-2 regions of the rDNA gene of Macrogyrodactylus spp. and Laminiscus gussevi (Bychowsky et Polyanky, 1953) from the 810 bp long alignment. Values below the diagonal are expressed in percentage (p-distance) while values above the diagonal represent number of differences in nucleotides. Newly sequenced taxa are in bold.

\begin{tabular}{|c|c|c|c|c|c|c|c|c|c|c|c|c|c|c|c|c|c|c|c|}
\hline & & 1 & 2 & 3 & 4 & 5 & 6 & 7 & 8 & 9 & 10 & 11 & 12 & 13 & 14 & 15 & 16 & 17 & 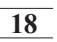 \\
\hline 1 & GU252711 Macrogyrodactylus clarii ZI & & 0 & 0 & 0 & 4 & 3 & 7 & 7 & 9 & 76 & 75 & 54 & 72 & 69 & 69 & 91 & 159 & \\
\hline 2 & MZ869846 Macrogyrodactylus clarii isolate $1 \mathrm{ZM}$ & 0.0 & & 0 & 0 & 4 & 3 & 6 & 6 & 8 & 68 & 68 & 54 & 68 & 67 & 67 & 79 & 113 & 15 \\
\hline 3 & MZ869850 Macrogyrodactylus clarii isolate $2 \mathrm{ZM}$ & 0.0 & 0.0 & & 0 & 4 & 3 & 7 & 7 & 9 & 75 & 74 & 54 & 71 & 69 & 74 & 87 & 125 & 160 \\
\hline 4 & MZ869847 Macrogyrodactylus clarii isolate $3 \mathrm{ZM}$ & 0.0 & 0.0 & 0.0 & & 4 & 3 & 7 & 7 & 9 & 76 & 75 & 54 & 71 & 69 & 74 & 88 & 126 & 162 \\
\hline 5 & GU25 & 0.5 & 0.6 & 0.6 & 0.6 & & 9 & 5 & 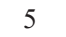 & 7 & 74 & 73 & 52 & 72 & 69 & 75 & 89 & 156 & 198 \\
\hline 6 & MZ8 & 0.4 & 0.5 & 0.4 & 0.4 & 0.1 & & 4 & 4 & 6 & 68 & 67 & 51 & 69 & 68 & 71 & 79 & 116 & \\
\hline 7 & GU2 & 0.9 & 0.9 & 1.0 & 1.0 & 0.7 & 0.6 & & 0 & 4 & 75 & 74 & 51 & 71 & 68 & 76 & 88 & 160 & 197 \\
\hline 8 & HF5 & 1.0 & 0.9 & 1.0 & 1.0 & 0.7 & 0.6 & 0.0 & & 4 & 70 & 69 & 51 & 69 & 68 & 73 & 79 & 119 & 15 \\
\hline 9 & GU2 & 1.2 & 1.2 & 1.3 & 1.3 & 0.9 & 0.9 & 0.5 & 0.6 & & 74 & 73 & 50 & 70 & 67 & 75 & 87 & 15 & 19 \\
\hline 10 & GU2 & 10.3 & 10.3 & 11.0 & 11.1 & 10.1 & 10.1 & 10.2 & 10.4 & 10.1 & & 2 & 5 & 30 & 27 & 23 & 69 & 147 & 19 \\
\hline 11 & GU2 & 10.2 & 10.3 & 10.9 & 11.0 & 9.9 & 10 & 10.1 & 10.3 & 9.9 & 0.3 & & 4 & 28 & 26 & 23 & 68 & 145 & 19 \\
\hline 12 & IZ86 & 8.6 & 8.6 & 8.6 & 8.6 & 8.3 & 8.1 & 8.1 & 8.1 & 7.9 & 0.8 & 0.6 & & 11 & 12 & 10 & 51 & 81 & 135 \\
\hline & $\mathrm{U} 2$ & 9 & 10.3 & 10.4 & 10.4 & 9.8 & 10.3 & 9.7 & 10.3 & 9.5 & 4.1 & 3.8 & 1.7 & & 1 & 14 & 75 & 144 & 197 \\
\hline & IZ8 & 10.3 & 10.2 & 10.3 & 10.3 & 10.3 & 10 & 10.1 & 10.1 & 10.0 & 4.0 & 3.9 & 1.9 & 0.1 & & 12 & 75 & 102 & 157 \\
\hline 1 & IZ86 & & 10.2 & 10.5 & 10. & 10.9 & 10.6 & 11 & 10. & 10.9 & 3.3 & 3.3 & 1.6 & 2.0 & 1.8 & & 72 & 119 & 168 \\
\hline & 156 & 1 & 12.0 & 12 & 12 & 12. & 11. & 12.3 & 11.8 & 12.1 & 9.6 & 9.5 & 8.1 & 10.5 & 10.3 & 10.5 & & 134 & \\
\hline & HF548 & & 18.5 & 19.7 & 19.8 & 22. & 18. & 23 & 19 & 23 & 21. & 21. & 21.3 & 21.2 & 18 & & 20.0 & & \\
\hline & HF548678 Laminiscus gt & & & & & & & & 24 & 27. & & & & & & & & 9.8 & \\
\hline
\end{tabular}

Abbreviations: IC -Iceland, KY - Kenya, M. - Macrogyrodactylus, SN - Senegal, SA - South Africa, ZI - Zimbabwe, ZM - Zambia.

Voucher material: Four voucher specimens deposited in, NMB P 818-821.

Representative DNA sequences: 715-741 bp long sequence of the ITS1-5.8S-ITS2 region of the rRNA gene of two isolates. GenBank accession numbers: MZ869845, MZ869851. Hologenophore, NMB P 829.

Specimens studied: $\mathrm{n}=8$ (KuShokwe Pan, SA), $\mathrm{n}=1$ (Usuthu River, SA), $\mathrm{n}=2$ (Barotse floodplain, ZM).

Infection rate: KuShokwe Pan (SA): $\mathrm{P}=20 \%$, IF $=1-2$; Usuthu River (SA): $\mathrm{P}=66 \%, \mathrm{IF}=1$; Barotse floodplain $(\mathrm{ZM})$ $\mathrm{P}=6 \%, \mathrm{IF}=1$.

Morphological observations (measurements provided in Table 6): General morphology of the haptoral sclerites is similar to the description of Douëllou and Chishawa (1995). Marginal hook sickle blade slender and inwardly curved point, distal side slightly convex as it joins sickle blade. Base of sickle presents noticeable curvature toward anterior end of sickle, has a convex distal side with an indentation as it joins sickle blade that sharply curve inward, tapering into a sharp point that stops before proximal side of sickle base; proximal side of sickle base curved. Cirrus observed in two specimens from KuShokwe Pan (SA) and Barotse floodplain (ZM), respectively, armed with 15 small spines and one large spine (Fig. 2I).

Remarks. Macrogyrodactylus karibae can be easily distinguished from M. congolensis in having a ventral bar with short anterolateral processes and a short central arm. It can also be distinguished from $M$. clarii in having slender hamuli that is sharply curved into the point and root and in having a single uniform dorsal bar, wider than long (see Figs. 2G-H, 3C). Additionally, M. karibae presents a curved proximal side of sickle base, opposed to the absence of a curved appearance in M. clarii and M. congolensis (Fig. 2H and Fig. 3D(iii)).

Dimensions for the hamuli (total length, point, shaft and root length) for specimens in the present study from NGR (SA) and Barotse floodplain (ZM) are within the ranges reported for the same species from other localities in southern Africa (Table 6) (Douëllou and Chishawa 1995, Khalil and Mashego 1998, Barson et al. 2010). The size of the dorsal and ventral bars is within the size ranges previously reported. The marginal hook size and morphology are comparable to previously reported data, specimens from NGR seem to have a slightly larger marginal hook sickle than previously reported. In the description and re-evaluation of M. karibae, Douëllou and Chishawa (1995) and Khalil and Mashego (1998) did not provide details on the morphology of the marginal hooks, which are provided in the present study. Comparative measurements are presented in Table 6.

\section{Phylogenetic relationships}

Seven sequences (696-753 bp long) of the ITS1-5.8SITS2 region of the rRNA gene of Macrogyrodactylus spp. from $C$. gariepinus were newly generated in the present study (see Table 3 for detailed information). Maximum likelihood and Bayesian inference analyses yielded trees with similar topology (Fig. 4). The genetic distances presented as p-distance (in \%) and number of differences in nucleotides among Macrogyrodactylus spp. and the outgroup are given in Table 7. The tree depicted a separated branch with Macrogyrodactylus simentiensis Přikrylová et Gelnar, 2008 from a polypterid, one single branch with Macrogyrodactylus polypteri also from a polypterid, and a clade grouping Macrogyrodactylus spp. from clariids that divided into two subclades. The first subclade shows that M. clarii isolates 1, 2 and 3 from ZM that clustered together with $M$. clarii from Zimbabwe (ZI) (GU252711) are all identical, whereas $M$. clarii isolate 1 from SA is more related to $M$. clarii $\times$ heterobranchii from ZI (GU252713) showing slight interspecific differences (p-distance $0.1-$ $0.5 \%$, number of differences in nucleotides $1-3) ; M$. clarii $\times$ heterobranchii (GU252713 and HF548583) from Kenya $(\mathrm{KY})$ and Senegal $(\mathrm{SN})$ appeared closely related to 


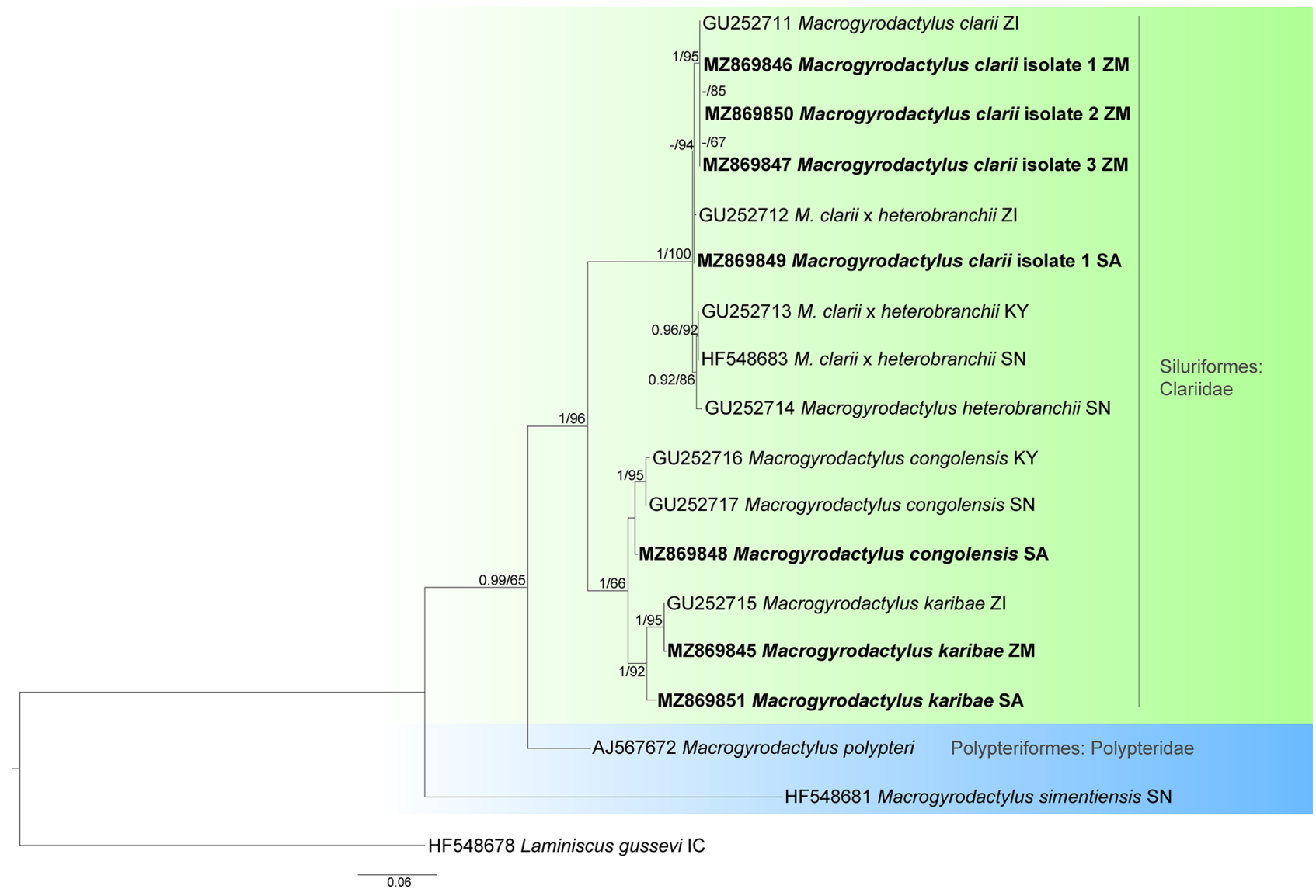

Fig 4. Maximum likelihood phylogram based on the ITS1-5.8S-ITS2 regions of the rDNA gene. GenBank accession number precedes species name. Species sequenced in the present study are in bold. Posterior probabilities and bootstrap support values are presented along branch nodes (posterior probability $<0.90$ and bootstrap $<60$ are not shown). Laminiscus gussevi (Bychowsky et Polyansky, 1953) was used as outgroup. Branch length scale bar indicates number of substitutions per site. Abbreviations: IC - Iceland; KY - Kenya; M. - Macrogyrodactylus; SA - South Africa; SN - Senegal; ZI - Zimbabwe; ZM - Zambia.

M. heterobranchii from SN (p-distance 0.5-0.6\%, number of differences in nucleotides 4). The second subclade showed that M. congolensis and M. karibae are closely related. Macrogyrodactylus congolensis isolate from KY (GU252716) and from SN (GU252717) appeared more related (p-distance $0.3 \%$, number of differences in nucleotides 2), whereas the isolate from SA showed interspecific divergence ( $\mathrm{p}$-distance $0.6-0.8 \%$, number of differences in nucleotides 4-5); $M$. karibae from ZM appeared more related to M. karibae from ZI (GU252715) (p-distance 0.1\%, number of differences in nucleotides 1) whereas $M$. karibae from SA showed more interspecific divergence (p-distance $1.8-2 \%$, number of differences in nucleotides $12-14$ ).

\section{DISCUSSION}

Novel distribution records for Macrogyrodactylus clarii, M. congolensis and M. karibae are confirmed in southern Africa. The presence of the three Macrogyrodactylus spp. in the Vaal River and NGR (SA), and from the Barotse floodplain and Kabompo River (ZM) reflect similar community composition of species as in other localities in southern Africa and Africa (Khalil and Mashego 1998, Barson et al. 2008, 2010, Olivier et al. 2009, Madanire-Moyo et al. 2012). The absence of Macrogyrodactylus species in the Eastern and Western Cape in the South Cape ichthyo- faunal province confirms that Macrogyrodactylus was not co-introduced with Clarias gariepinus from the Zambezi and northern regions of the Southern Cape ichthyofaunal provinces, the geographical origin of these translocated C. gariepinus populations (see Van Steenberge et al. 2019 and references therein). This implies that $C$. gariepinus in the translocated regions initially did not harbour any species of Macrogyrodactylus and is supported by the absence of Macrogyrodactylus spp. in the Free State, the southernmost limit of the host's natural distribution. These results suggest that the parasite is either naturally absent from these systems, seasonally present or absent, or restricted by environmental barriers such as physicochemical variables and organic pollution (see Khan and Thulin 1991, Madanire-Moyo and Barson 2010, Madanire-Moyo et al. 2012, Gilbert and Avenant-Oldewage 2017, Sures et al. 2017).

The findings of the present study represent infection intensities in a single point in time and did not indicate high numbers or cause for concern as reported by Khalil and Mashego (1998). The host specimens from the Vaal River (SA) and Barotse floodplain (ZM) that had the highest worm burden (109 individuals of Macrogyrodactylus spp. each), did not present greyish-white patches on the skin, as previously recorded by the aforementioned authors in cases of severe infection in natural conditions. Infection of 
C. gariepinus with M. clarii, M. congolensis and M. karibae found in this study is low if compared to reports from the Middle Letaba Dam (SA) where intensities of M. clarii peaked from 1 to 700 during summer months, and $M$. $k a$ ribae numbers increased up to 150 (while $M$. clarii decreased) during the cooler months of autumn. The co-occurrence of $M$. clarii and M. karibae, the latter in fewer numbers, reported from the Middle Letaba Dam coincides with findings from KuShokwe Pan, South Africa (Khalil and Mashego 1998). From available data, it seems that M. clarii is an ever-present species occurring at all, but one locality studied in the southern African region (Khalil and Mashego 1998, Barson et al. 2008, Barson 2009, Madanire-Moyo 2011).

The use of universal primers for the ITS region of the rDNA and its suitability as a diagnostic tool made it widely used within gyrodactylid systematics, resulting in the availability of many sequences for this group (Matějusová et al. 2003, Přikrylová et al. 2013). The first study to ever sequence the ITS region of a Macrogyrodactylus species (Macrogyrodactylus polypteri) was conducted by Matějusová et al. (2003). These authors constructed a phylogeny including sequences of many species of Gyrodactylus von Nordmann, 1832, and a sequence of Gyrdicotylus gallieni (Vercammen Grandjean, 1960), and Gyrodactyloides bychowsii Albova, 1948. Their phylogenetic analyses recovered M. polypteri as the closest ancestor of Gyrodactylus, as suggested by Malmberg (1998) based on morphological characteristics, who also suggest that Macrogyrodactylus is supposed to be the earliest divergent gyrodactylid lineage. However, Malmberg's hypothesis has recently been refuted by Vanhove et al. (2018), who analysed the near-complete mitogenome of $M$. karibae and compared it with other gyrodactylid genera.

Barson et al. (2010) was the second study to include molecular analyses of the ITS region for Macrogyrodactylus spp., including for the first time M. clarii, M. congolensis, $M$. heterobranchii and M. karibae from African clariids. Sequences of the partial 18S rDNA, complete ITS and the mitochondrial gene $\operatorname{cox} 1$, together with morphology revealed a hybrid species that was intermediate between M. clarii and M. heterobranchii, which was confirmed by their phylogenetic analyses (Barson et al. 2010). Přikrylová et al. (2013) conducted a large-scale phylogenetic study on African gyrodactylids, including for the first time sequences of the 18S and ITS rDNA of all (but one) genera occurring in the continent. Both ITS and 18S phylogenetic analyses of Přikrylová et al. (2013) recovered, with strong support, Macrogyrodactylus as a monophyletic group. Boeger et al. (2021) in their phylogenetic study based on $18 \mathrm{~S}$ rDNA sequences of several gyrodactylid genera also recovered Macrogyrodactylus as a monophyletic lineage related to Diplogyrodactylus Přikrylová, Matějusová, Musilová, Gelnar et Harris, 2009 and Afrogyrodactylus Paperna, 1968. In contrast, Macrogyrodactylus appeared related to Paragyrodactylus Gvozdev et Martechov, 1953 in their analyses of the mitochondrial gene cox2.

The clustering of Macrogyrodactylus from clariid hosts as two distinctive lineages in the phylogenetic analyses in this study reflects their morphological synapomorphies. Macrogyrodactylus clarii and $M$. heterobranchii share the following morphological characteristics: 1) hamuli with a strong inward curvature in the root, 2) a divided dorsal bar with two articulating sections, 3) a ventral bar with two short anterolateral arms and a long central posterior arm, and, 4) slender marginal hook sickle and slender sickle blade tapering into a sharp, thin point ending in line with the anterior end of the sickle base.

Macrogyrodactylus congolensis and M. karibae share the following morphological characteristics: 1) hamuli with slight inward curvature of the root, 2) single undivided dorsal bar, and 3) robust marginal hook sickle and short sickle blade tapering into a fine point that end in line with the proximal end of the sickle base. However, the relationships of Macrogyrodactylus from polypterids remained inconclusive in the present study.

The phylogenetic analyses showed that the ITS-1-5.8SITS-2 sequences of $M$. clarii from South Africa differed slightly from those of $M$. clarii from Zambia and Zimbabwe; similarly, M. congolensis from South Africa differed slightly from $M$. congolensis from Kenya and Senegal (see Fig. 4 and Table 7 for genetic distances). The ITS1-5.8S-ITS-2 sequences of $M$. karibae from South Africa also differed from those of M. karibae from Zambia and Zimbabwe (Fig. 4, Table 7). Such differences can be related to the geographical separation of the hosts among the African ichthyofaunal provinces of Zambezi and Southern (Cape) as proposed by Roberts (1975), Teugels (1986) and Van Steenberge et al. (2019) and references therein. Clarias gariepinus inhabiting the Southern Cape retains similar haplotypes as those from the central and eastern Zambezi Province, thus these catfish occurred sympatrically before a recent separation into the Southern Cape and brought along their parasites (Barson et al. 2010, Van Steenberge et al. 2019).

There is still disproportionate availability of data on freshwater fish parasite diversity from Africa. The continent holds $\sim 25 \%$ of the world's freshwater fishes (with the second highest species richness on the globe), and some of the most widely distributed endemic freshwater species (Scholz et al. 2018). It is also evident that there is disparity in distribution and diversity records throughout the continent, even from a widely distributed fish host such as C. gariepinus. No data on its parasitic communities exist from at least 3/4 of African countries, where this fish is either native or translocated, and highly utilised for aquaculture. Therefore, more studies encompassing occurrence, environmental or seasonal variation, morphology and genetics of Macrogyrodactylus spp. are necessary to better understand their distribution and irradiation into the African continent.

Acknowledgements. This work is based on the research and researchers supported by the National Research Foundation (NRF) - South African Research Chairs Initiative of the Department of Science and Innovation (DSI) (Inland Fisheries and Freshwater Ecology, Grant no. 110507) and National Research Foundation (NRF) of South Africa (Project CPRR160429163437; P.I.: N.J. Smit). Opinions, findings, conclusions and recommendations 
expressed in this publication is that of the authors, and the NRF accepts no liability whatsoever in this regard. We acknowledge use of infrastructure and equipment provided by the NRF-SAIAB Research Platforms and the funding channelled through the NRFSAIAB Institutional Support system. The authors are grateful to two anonymous reviewers whose comments and corrections significantly improved the manuscript. The authors would like to thank Ezemvelo KZN Wildlife (KwaZulu-Natal, permit Nos. OP 1075/2017, OP 1582/2018); the Department of Rural, Environmental and Agricultural Development (North West, permit no. HO 20/02/18-057 NW); the Department of Economic, Small Business Development, Tourism and Environmental Affairs (DESTEA, Free State, permit no. JM 4066/2018); the Department of Economic Development, Environmental Affairs and Tourism (Eastern Cape, permit no. CRO 20/18CR, CRO 22/18CR) and CapeNature (Western Cape, permit no. CN44-31-6790) for ap- proving permits for collection of fish in the respective provinces. The support of Leon Barkhuizen and his team (DESTEA, Free State) for collection of host specimens is greatly appreciated. The Ministry of Fisheries and Livestock (Department of Fisheries, Mongu, Zambia) and World Wide Fund for Nature (WWF, Zambia) is thanked for their support and permission for joint research in the Upper Zambezi Basin, Zambia. The authors also extend their gratitude to Craig Rennie, Takudzwa Comfort Madzivanzira, and Josie South from SAIAB, Machaya Chomba, Kakoma Chinyawezhi (WWF, Zambia), and local liaison Fidelis Mutukelwa and Namunda Namunda (Mongu Harbour Master, Zambia), and the following Water Research Group members: Anrich Kock and Ruan Gerber, Chantelle Pretorius, Coret Hoogendoorn and Grietjie Stander for their support during fieldwork. This is contribution No. 557 from the NWU-Water Research Group.

\section{REFERENCES}

Akoll P., Konecny R., Mwanja W.W., Nattabi J.K., Agoe C., Schiemer F. 2012: Parasite fauna of farmed Nile tilapia (Oreochromis niloticus) and African catfish (Clarias gariepinus) in Uganda. Parasitol. Res. 110: 315-323.

Amirthalingam C. 1965: Macrogyrodactylus polypteri Malmberg on Polypterus senegalus in the Sudan. Bull. Fish. Res. Stn. Ceylon 17: 237-239.

ArAfA S.Z.E. 2000: Spermiogenesis and sperm ultrastructure of the fish ectoparasite Macrogyrodactylus congolensis (Prudhoe, 1957) Yamaguti 1963 (Trematoda, Monogenea). J. Union Arab. Biol. 14: 619-629.

ArAFA S.Z. 2011: Ultrastructure of musculature of the marginal hooklets of Macrogyrodactylus congolensis, a monogenean skin parasite from the catfish Clarias gariepinus. Acta Parasitol. 56: $122-130$.

Arafa S.Z., El-Hady E.K.A., El-Abbassy S.A. 2012: Histochemical demonstration of five enzymes' activities in Macrogyrodactylus clarii (Monogenea: Gyrodactylidae) from the catfish Clarias gariepinus. Folia Parasitol. 59: 43-52.

Arafa S.Z., El-Naggar M.M., El-Abbassy A. 2009: Mode of attachment and histopathological effects of Macrogyrodactylus clarii, a monogenean gill parasite of the catfish Clarias gariepinus, with a report on host response. Acta Parasitol. 54: 103-112.

Arafa S.Z., El-Naggar M.M., Kearn G.C. 2003: Scanning electron microscope observations on the monogenean skin parasite Macrogyrodactylus congolensis (Prudhoe, 1957) Yamaguti, 1963. Acta Parasitol. 48: 163-171.

Arafa S.Z., El-Naggar M.M., Kearn G.C. 2013: Ultrastructure of the digestive system and experimental study of feeding in the monogenean skin and fin parasite Macrogyrodactylus congolensis. Acta Parasitol. 58: 420-433.

Arafa S.Z., El-Naggar M.M., Kearn G.C. 2014: On some ultrastructural features of the reproductive system of the monogenean parasite Macrogyrodactylus congolensis from Clarias gariepinus inhabiting the River Nile in Egypt. Acta Parasitol. 59: 238-246.

Bakke T.A., Harris P.D., Cable J. 2002: Host specificity dynamics: observations on gyrodactylid monogeneans. Int. J. Parasitol. 32: $281-308$.

BARson M. 2009: Diversity and ecology of fishes and their helminth parasites in a subtropical river system (Save-Runde River, Zimbabwe). PhD thesis, Katholieke Universiteit Leuven, 145 pp.

Barson M., Bray R., Ollevier F., Huyse T. 2008: Taxonomy and faunistics of helminth parasites of Clarias gariepinus (Burchell, 1822) and Oreochromis mossambicus (Peters, 1852) from temporary pans and pools in the Save-Runde River Floodplain, Zimbabwe. Comp. Parasitol. 75: 228-240.
Barson M., Přikrylová I., VAnhove M.P.M., Huyse T. 2010: Parasite hybridization in African Macrogyrodactylus spp. (Monogenea, Platyhelminthes) signals historical host distribution. Parasitology 137: 1585-1595.

Beletew M., Getahun A., Vanhove M.P.M. 2016: First report of monogenean flatworm from Lake Tana, Ethiopia: gill parasites of the commercially important Clarias gariepinus (Teleostei: Clariidae) and Oreochromis niloticus tana (Teleostei: Cichlidae). Parasit. Vectors 9: 410.

Boeger W.A., Kritsky D.C., Patella L., Bueno-Silva M. 2021: Phylogenetic status and historical origins of the oviparous and viviparous gyrodactylids (Monogenoidea, Gyrodactylidea). Zool. Scr. 50: 112-124.

Boeger W.A., Kritsky D.C., Pie M.R. 2003: Context of diversification of the viviparous Gyrodactylidae (Platyhelminthes, Monogenoidea). Zool. Scr. 32: 437-448.

Bush A.O., Lafferty K.D., Lotz J.M., Shostak A.W. 1997: Parasitology meets ecology on its own terms: Margolis et al. revisited. J. Parasitol. 83: 575-583.

Cable J., Harris P.D., Tinsley R.C. 1996: Ultrastructural adaptations for viviparity in the female reproductive system of gyrodactylid monogeneans. Tissue Cell 28: 515-526.

Cribb T.H., Chisholm L.A., Bray R.A. 2002: Diversity in the Monogenea and Digenea: does lifestyle matter? Int. J. Parasitol. 32: $321-328$.

Douëllou L., Chishawa, A.M.M. 1995: Monogeneans of three siluriform fish species in Lake Kariba, Zimbabwe. J. Afr. Zool. 109: 99-115.

EL-NAGGAR M.M. 1993: Scanning electron microscope observations on the head lobes and haptor of the monogenean Macrogyrodactylus clarii Gussev, 1961. J. Egypt. Ger. Soc. Zool. 10: $143-155$.

El-Naggar M.M., Arafa S.Z., El-Abbassy S.A., Kearn G.C. 2001a: Chaetotaxy of the monogeneans Macrogyrodactylus clarii and $M$. congolensis from the gills and skin of the catfish Clarias gariepinus in Egypt, with a note on argentophilic elements in the nervous system. Folia Parasitol. 48: 201-208.

El-Naggar M.M., Arafa S.Z., El-Abbassy S A., Kearn G.C. 2001b: Microhabitat and movement of the viviparous monogeneans Gyrodactylus alberti, Macrogyrodactylus clarii and M. congolensis from the Nile catfish Clarias gariepinus. J. Egypt. Ger. Soc. Zool. 35: 169-187.

El-Naggar M.M., Arafa S.Z., El-Abbassy S A., Kearn G.C., CABLE J. 2019: Ultrastructure of the anterior adhesive apparatus of the gill parasite Macrogyrodactylus clarii and skin parasite M. congolensis (Monogenea: Gyrodactylidae) from the catfish Clarias gariepinus. Parasitol. Int. 71: 151-159. 
El-Naggar M.M., Arafa S.Z., El-Abbassy S.A., Kearn G.C., CABLE J. 2020: Light and transmission electron microscopy of the haptoral sclerites of the monogenean gill parasites Macrogyrodactylus clarii. Parasitol. Res. 119: 4089-4101.

El-Naggar M.M., Arafa S.Z., El-Abbassy S.A., Stewart M.T., HALton D.W. 2004a: Neuromusculature of the Nile catfish Clarias gariepinus in Egypt. Parasitol. Res. 94: 163-175.

El-Naggar M.M., Arafa S.Z., El-Abbassy S.A., Stewart M.T., Halton D.W. 2007: Neuromusculature of Macrogyrodactylus congolensis, a monogenean skin parasite of the Nile catfish Clarias gariepinus. Parasitol. Res. 100: 265-279.

El-NAGgaR M.M., CABLE J. 2007: Ultrastructural observations on the elusive subtegumental cells of the viviparous gill monogenean, Macrogyrodactylus clarii. Parasitol. Res. 101: 9-17.

El-Naggar M.M., Cable J., Arafa S.Z., El-Abbassy S.A., KeARN G.C. 2016: Scanning and transmission electron microscopy of the histopathological impact of Macrogyrodactylus clarii (Monogenea: Gyrodactylidae) on the gills of catfish, Clarias gariepinus. Folia Parasitol. 63: 017.

El-Naggar M.M., El-Naggar A.A., Kearn G.C. 2004b: Swimming in Gyrodactylus rysavyi (Monogenea, Gyrodactylidae) from the Nile catfish, Clarias gariepinus. Acta Parasitol. 49: $102-107$

El-Naggar M.M.M., Hagras A.E.M., Mansour M.F.A., EL-NAGGAR A.M. 1997: Microhabitat distribution and coexistence of the monogenean gill parasites of the Nile catfish Clarias lazera. J. Environ. Sci. 13: 227-243.

El-Naggar M.M., Kearn G.C., Hagras A.E., Arafa S.Z. 1999: On some anatomical features of Macrogyrodactylus congolensis, a viviparous monogenean ectoparasite of the catfish Clarias gariepinus from Nile water. J. Egypt. Ger. Soc. Zool. 29: 1-24.

El-Naggar M.M., Mashalay M.I., Hagras A.M., Alshafei H.A. 2017: Monogenean microfauna of the Nile catfish, Clarias gariepinus as biomonitors of environmental degradation in aquatic ecosystems at the Nile Delta, Egypt. J. Environ. Sci. Toxicol. Food Technol. 11: 45-62.

El-Naggar M.M., Serag H.M. 1987: Redescription of Macrogyrodactylus clarii Gussev, 1961 a monogenean gill parasite of Clarias lazera in Egypt. Arab Gulf J. Sci. Res. Agricult. Biol. Sci. B5: 257-271.

El-Seify M.A., Zaki M.S., Desouky A.R.Y., Abbas H.H., АвDel Hady O.K., АвоU Zaid A.A. 2018: Seasonal variations and prevalence of some external parasites affecting freshwater fishes reared at upper Egypt. In: V. Kumar, M. Kumar, R. Prasad (Eds.) Phytobiont and Ecosystem Restitution. Springer, Singapore, pp.175-183.

ERGENS R. 1969: The suitability of ammonium picrate-glycerin in preparing slides of lower Monogenoidea. Folia Parasitol. 16: 320

Eyo V.O., Edet T.A., Ekanem A.P. 2015: Monogenean parasites of the African catfish Clarias gariepinus from two fish farms in Calabar, Cross River State, Nigeria. J. Coast. Life Med. 3: 433-437.

Gilbert B.M., Avenant-Oldewage A. 2017: Parasites and pollution: the effectiveness of tiny organisms in assessing the quality of aquatic ecosystems, with a focus in Africa. Environ. Sci. Pollut. Res. 24: 19742-18769.

Guindon S., Gascuel O. 2003: A simple, fast, and accurate algorithm to estimate large phylogenies by maximum likelihood. Syst. Biol. 52: 696-704.

Gussev A.B. 1961: [Aviviparous monogenetic trematode from freshwater basins of Africa]. Doklady Akademii nauk SSSR, 136: 490-493. (In Russian.)

Hagras A.E., El-Naggar M.M., Kearn G.C., Arafa S.Z. 1999: Monthly occurrence, seasonal population dynamics and distribution of four monogeneans on the catfish Clarias gariepinus in Dakahlia province, lower Egypt. J. Egypt. Ger. Soc. Zool. 29(D): 49-66.

Hagras A.E.M., El-NagGar M.M., Mansour M.F.A., El-NaGGAR A.M. 1995: Influence of age, length and sex of the catfish
Clarias lazera on infestation with six monogenean parasites. Mans. Sci. Bull. (B Biology) 22: 37-56.

Khan R.A., Thulin J. 1991: Influence of pollution on parasites of aquatic animals. Adv. Parasitol. 30: 201-319.

Kearse M., Moir R., Wilson A., Stones-Havas S., Cheung M., Sturrock S., Buxton S., Cooper A., Markowitz S., Duran C., Thierer T., Ashton B., Meintjes P., DrumMOND A. 2012: Geneious Basic: an integrated and extendable desktop software platform for the organization and analysis of sequence data. Bioinformatics 28: 1647-1649.

KHALIL L.F. 1964: On the biology of Macrogyrodactylus polypteri Malmberg, 1956, a monogenetic trematode on Polypterus senegalus in the Sudan. J. Helminthol. 38: 219-222.

KhaliL L.F. 1970: Further studies on Macrogyrodactylus polypteri, a monogenean on the African freshwater fish Polypterus senegalus. J. Helminthol. 44: 329-348.

Khalil L.F., Mashego S.N. 1998: The African monogenean gyrodactylid genus Macrogyrodactylus Malmberg, 1957, and the reporting of three species of the genus on Clarias gariepinus in South Africa. Onderstepoort J. Vet. Res. 65: 223-231.

Kumar S., Stecher G., Tamura K. 2016: MEGA7: Molecular Evolutionary Genetics Analysis version 7.0 for bigger datasets. Mol. Biol. Evol. 33: 1870-1874.

Madanire-Moyo G. 2011: A comparative study of ecosystem health of selected water bodies in the Olifants and Limpopo River systems using the health assessment index and parasite diversity as indicators. PhD Thesis, Polokwane, University of Limpopo, $244 \mathrm{pp}$.

Madanire-Moyo G.N., Barson M. 2010: Diversity of metazoan parasites of the African catfish Clarias gariepinus (Burchell, 1822 ) as indicators of pollution in a subtropical African river system. J. Helminthol. 84: 216-227.

Madanire-Moyo G.N., Luus-Powell W.J., Jooste A., OlivIER P.A.S. 2012: A comparative assessment of the health status of feral populations of Clarias gariepinus from three dams in the Limpopo and Olifants river systems, Limpopo province, South Africa, using the fish health assessment index protocol. Afr. J. Aquat. Sci. 37: 27-37.

Madanire-Moyo G.N., Luus-Powell W.J., Olivier P.A.S. 2010: Ecology of metazoan parasites of Clarias gariepinus (Osteichthyes: Clariidae) from the Nwanedi-Luphephe Dams of the Limpopo River System, South Africa. Afr. Zool. 45: 233-243.

MahlatJi M.L. 2014: The impact of water and sediment quality on the health of Clarias gariepinus (Burchell, 1822) and Labeo rosae (Steindachner, 1894) at the Phalaborwa Barrage, Olifants River, Limpopo Province. PhD Thesis, Limpopo, University of Limpopo, 110 pp.

Malmberg G. 1970: The excretory systems and the marginal hooks as a basis for the systematics of Gyrodactylus (Trematoda, Monogenea). Ark. Zool. 23: 1-235.

MalmberG G. 1998: On the evolution within the family Gyrodactylidae (Monogenea). Int. J. Parasitol. 28: 1625-1635.

Mashalay M.I., El-Naggar A.M., Hagras A.E., Alshafei H.A. 2019: Microhabitat selection of ectoparastic monogenean populations of the Nile catfish, Clarias gariepinus. Jordan J. Biol. Sci. 12: 573-580.

Matěuusová I., Gelnar M., McBeath A.J.A., Collins C.M., CunNingham C.O. 2001: Molecular markers for gyrodactylids (Gyrodactylidae: Monogenea) from five fish families (Teleostei). Int. J. Parasitol. 31: 738-745.

Matějusová I., Gelnar M., Verneau O., Cunningham C.O., LitTLEWood D.T.J. 2003: Molecular phylogenetic analysis of the genus Gyrodactylus (Platyhelminthes: Monogenea) inferred from rDNA ITS region: subgenera versus species groups. Parasitology 127: 603-611.

Matla M.M. 2012. Helminth ichthyo-parasitic fauna of a South African sub-tropical lake, University of Limpopo, South Africa. PhD Thesis, Polokwane, University of Limpopo, $281 \mathrm{pp}$.

Miller M.A., Pfeiffer W., Schwartz T. 2010: Creating the CIPRES Science Gateway for inference of large phylogenet- 
ic trees. Gateway Computing Environments Workshop (GCE), New Orleans, Louisiana, 14 November 2010, 1-8.

N'Douba V., LAmbert A. 1999: Un nouveau Macrogyrodactylus (Monogenea, Gyrodactylidae) parasite de Heterobranchus longifilis Valenciennes, 1840 (Téléostéen, Silurifomes) en Côte d'Ivoire. Zoosystema 21: 7-11.

Obiekezie A.L., Ajah P.O. 1994: Chemotherapy of macrogyrodactylosis in the culture of African clariid catfishes Clarias gariepinus and Heterobranchus longifilis. J. Aqua Trop. 9: 187-192.

Olivier P.A.S., Luus-Powel W.J., Saayman J.E. 2009: Report on some monogenean and clinostomid infestations of freshwater fish and waterbird hosts in Middle Letaba Dam, Limpopo Province, South Africa. Onderstepoort J. Vet. Res. 76: 187-199.

Paperna I. 1969: Monogenetic trematodes of the fish of the Volta basin and South Ghana. Bulletin du I'I. F. A. N., Ser A, No. 3 , 31: 840-880

Paperna I. 1973: New species of Monogenea (Vermes) from African freshwater fish. A preliminary report. Rev. Zool. Bot. Afr. 87: 505-518.

Paperna I. 1979: Monogenea of inland water fish in Africa. Koninklijk Museum voor Midden-Afrika, Terveuren, Belgie Annalen, Zoolgische Wetenschkappen, Ser. 8, 226: 79-131.

Pleijel F., Jondelius U., Norlinder E., Nygren A., Oxelman B., Schander C., Sundberg P., Thollesson M. 2008 Phylogenies without roots? A plea for the use of vouchers in molecular phylogenetic studies. Mol. Phylogenet. Evol.48: 369-371.

Poulin R. 2002: The evolution of monogenean diversity. Int. J. Parasitol. 32: 245-254.

Přikrylová I., Gelnar M. 2008: The first record of Macrogyrodactylus species (Monogenea, Gyrodactylidae) on freshwater fishes in Senegal with the description of Macrogyrodactylus simentiensis sp. nov., a parasite of Polypterus senegalus Cuvier Acta Parasitol. 53: 1-8.

Přikrylová I., Shinn A.P., Paladini G. 2017: Description of Chitarodactylus gagei n. gen. et n. sp. (Monogenea: Gyrodactylidae) from the moon fish, Citharinus citharinus (Geoffroyy Saint-Hilaire), from Lake Turkana. Parasitol. Res. 116: 281-292.

Přikrylová I., Vanhove P.M., Janssens S.B., Billeter P.A., HUYSE T. 2013: Tiny worms from a mighty continent: high diversity and new phylogenetic lineages of African monogeneans. Mol. Phylogenet. Evol. 67: 43-52.

Prudhoe S. 1957: Trematoda: Exploration du Parc National de I'Upemba. Mission de Witte, G. F. en collaboration avec Adam, W., Janssens, A. van Meel, L., Verheyen, R. (1946-1949). Fascicule 48, Bruxelles, 1-28.

Radwan N.A., Khalil A.I., Eid M.A., Harras S.F. 2009: Aspects of the phylogeny of five species of Platyhelminthes based on tegumental ultrastructure and random amplified polymorphic DNA (RAPD-PCR) technique. Egypt. J. Exp. Biol. 5: 77-92.

Rambaut A. 2009: Molecular evolution, phylogenetics and epidemiology: Fig-Tree. World wide web electronic publication. http:// tree.bio.ed.ac.uk/software/figtree/.
ŘEHUlková E. 2018: Ectoparasitic helminths (Monogenea). In: T. Scholz, M.P.M. Vanhove, N. Smit, Z. Jayasundera and M. Gelnar (Eds.), A Guide to the Parasites of African Freshwater Fishes. ABC Taxa, pp. 18: 89-98.

Řehulková E., Seifertová M., Přikrylová I., Francová K. 2018: Monogenea. In: T. Scholz, M.P.M. Vanhove, N. Smit, Z. Jayasundera and M. Gelnar (Eds.), A Guide to the Parasites of African Freshwater Fishes. ABC Taxa, pp. 18: 185-243.

RoBERTs T.R. 1975: Geographical distribution of African freshwater fishes. Zool. J. Linn. Soc. 57: 249-319.

Ronquist F., Teslenko F.M., Van der Mark P., Ayres D.L., Darling A., Höhna S., Larget S.B., Liu L., Suchard M.A., Huelsenbeck J.P. 2012: MrBayes 3.2: efficient Bayesian phylogenetic inference and model choice across a large model space. Syst. Biol. 61: 539-542.

SAOUd M.F.A., MageEd A. 1969: Host-parasite relationships of Macrogyrodactylus polypteri (Trematoda: Monogenea) in some fishes of the Sudan. Curr. Sci. 38: 218-219.

Scholz T., Vanhove M.P.M, Smit N., Jayasundera Z., GelNAR M. (Eds.) 2018: A Guide to the Parasites of African Freshwater Fishes. ABC Taxa, 18: 420 pp.

Shotter A.R. 1980: Aspect of the parasitology of the catfish Clarias anguillaris (L.) from a river and a lake at Zaira, Kadune State, Nigeria. Bulletin de I' I. F. A. N., Ser. A, No. 4, 42: 836-859.

Sures B., Nachev M., Pahl M., Grabner D., Selbach C. 2017: Parasites as drivers of key processes in aquatic ecosystems: facts and future directions. Exp. Parasitol. 180: 141-147.

Teugels G.G. 1986: A systematic revision of the African species of the genus Clarias (Pisces; Clariidae). Ann. Mus. R. Afr. Centr., Sci. Zool. 247: 1-199.

Thurston J. 1970: The incidence of Monogenea and parasitic Crustacea on the gills of fish in Uganda. Rev. Zool. Bot. Afr. 82: $111-130$.

Vanhove M.P.M., Snoeks J., Volckaert F.A.M., Huyse T, 2011: First description of monogenean parasites in Lake Tanganyika: the cichlid Simochromis diagramma (Teleostei, Cichlidae harbours a high diversity of Gyrodactylus species (Platyhelminthes, Monogenea). Parasitology 138: 364-380.

Vanhove M.P.M., Briscoe A.G., Jorissen M.W., Littlewood D.T.J., HUYSE T. 2018: The first next-generation sequencing approach to the mitochondrial phylogeny of African monogenean parasites (Platyhelminthes: Gyrodactylidae and Dactylogyridae). BMC Genomics 19: 520.

Van Steenberge M.W., Vanhove M.P.M., Manda A.C., Larmuseau M.H.D., Swart B.L., Mate F.K., Arndt A., Hellemans B., Van Houdt J., Micha J.-C., Koblmüller S., Roodt-Wilding R., Volckaert F.A. M. 2019: Unravelling the evolution of Africa's drainage basins through a widespread freshwater fish, the African sharptooth catfish Clarias gariepinus. J. Biogeogr. 47: 1739-1754.

Cite this article as: Truter M., Acosta A.A., Weyl O.L.F, Smit N.J. 2021: Novel distribution records and molecular data for species of Macrogyrodactylus Malmberg, 1957 (Monogenea: Gyrodactylidae) from Clarias gariepinus (Burchell) (Siluriformes: Clariidae) in southern Africa. Folia Parasitol. 68: 027. 